\title{
The Effects of Trichoderma Fungi on the Tunneling, Aggregation, and Colony-Initiation Preferences of Black-Winged Subterranean Termites, Odontotermes formosanus (Blattodea: Termitidae)
}

\author{
Hongpeng Xiong ${ }^{1}$, Jiacheng Cai ${ }^{2}$, Xuan Chen ${ }^{3}$, Shiping Liang ${ }^{1}$, Xiujun Wen ${ }^{1}$ and Cai Wang ${ }^{1, *(D)}$ \\ 1 Guangdong Key Laboratory for Innovation Development and Utilization of Forest Plant Germplasm, \\ College of Forestry and Landscape Architecture, South China Agricultural University, Guangzhou 510642, \\ China; xionghp@stu.scau.edu.cn (H.X.); liangshiping@stu.scau.edu.cn (S.L.); wenxiujun@scau.edu.cn (X.W.) \\ 3 Department of Biology, Salisbury University, Salisbury, MD 21801, USA; xxchen@salisbury.edu \\ * Correspondence: wangcai@scau.edu.cn
}

Received: 14 October 2019; Accepted: 9 November 2019; Published: 13 November 2019

\begin{abstract}
The black-winged subterranean termite, Odontotermes formosanus Shiraki, is a severe pest of plantations and forests in China. This termite cultures symbiotic Termitomyces in the fungal combs, which are challenged by antagonistic microbes such as Trichoderma fungi. In a previous study we showed that O. formosanus workers made significantly fewer tunnels in sand containing commercially formulated conidia of Trichoderma viride Pers. ex Fries compared with untreated sand. Herein, we hypothesize that fungi in the genus Trichoderma exert repellent effects on $O$. formosanus. Different choice tests were conducted to evaluate the tunneling and aggregation behaviors of $O$. formosanus workers reacting to sand/soil containing the unformulated conidia of seven Trichoderma fungi (Trichoderma longibrachiatum Rifai, Trichoderma koningii Oud., Trichoderma harzianum Rifai, Trichoderma hamatum (Bon.) Bain, Trichoderma atroviride Karsten, Trichoderma spirale Indira and Kamala, and T. viride). We also investigated the colony-initiation preference of paired O. formosanus adults to soil treated with Trichoderma conidia (T. koningii or T. longibrachiatum) versus untreated soil. Tunneling-choice tests showed that sand containing conidia of nearly all Trichoderma fungi tested (except T. harzianum) significantly decreased tunneling activity in O. formosanus workers compared with untreated sand. Aggregation-choice test showed that T. koningii, T. atroviride and T. spirale repelled O. formosanus workers, whereas T. longibrachiatum and T. hamatum attracted termites. There was no significant difference in proportions of paired adults that stayed and laid eggs in the soil blocks treated with conidia of Trichoderma fungi and untreated ones. Our study showed that Trichoderma fungi generally repelled tunneling in O. formosanus, but may exert varied effects on aggregation preference by workers.
\end{abstract}

Keywords: Odontotermes formosanus; Trichoderma; subterranean termite; fungus-growing higher termite; termite-fungi interaction; choice test

\section{Introduction}

Termites are eusocial insects that feed on various types of cellulose. Based on foraging habitat or foraging environment, termites can be categorized into three types: (1) subterranean termites, which include wood-feeding lower termites and fungus-growing higher termites that construct underground nests or above-ground mounds attached the soil; (2) drywood termites, which live in and feed on dry wood above the soil levels; and (3) dampwood termites, which nest in the rotting wood with high 
moisture content. Among them, subterranean termites are the most economically important because many in this group are severe pests of in-service wood and living plants [1].

Subterranean termites are associated with high pathogen infection risk because of the high moisture environments of the soil they live in, which favor the growth of various entomopathogenic microbes [2]. Disease can spread rapidly among individuals in the limited space of an individual colony [2]. However, some studies have shown that subterranean termites have evolved many physiological mechanisms to deal with the challenges pathogens present. Hussain et al. [3] identified 439 immune-related sequences (i.e., pattern recognition receptors, signal modulators, signal transducers, and effectors) from Coptotermes formosanus Shiraki that were infected by entomopathogenic fungi and bacteria. Some termites and their symbiotic actinobacteria can produce various $\beta-1,3$-glucanases and antibiotics to prevent the germination of entomopathogenic fungi [4-6]. In addition, termites rely on altered behaviors to protect themselves from microbial pathogens. For example, the odor of entomopathogenic fungi has been shown to trigger alarm responses [7,8], grooming [8-11], attacking and cannibalism [12], cadaver burying [13], and spatial avoidance [14-17] in termites. These anti-pathogen responses, referred as "behavioral immunity" or "social immunity," have received increasing attention in recent years [18-21].

The black-winged subterranean termite, Odontotermes formosanus Shiraki, is a serious pest that can pose a threat to water holding facilities in China because they can move large amounts of soil in the construction of their nests, which can lead to subsurface voids inside dams and dikes [22]. Above ground level, this termite builds mud tubes and sheeting that cover the tree trunks where it consumes bark and phloem, leading to tree death. This is especially problematic with seedlings in plantations, forests, and urban green areas [23]. The survival of O. formosanus is not only challenged by entomopathogenic microbes, but by other microbes (e.g., Trichoderma spp., Aspergillus spp., and Penicillium spp.) that antagonize the lignocellulose-degrading fungi (Termitomyces spp.) cultured in the fungus combs of this termite [24]. Among them, Trichoderma fungi are well known to antagonize many plant pathogens based on multiple mechanisms (e.g., producing antibiotics, competing for nutrients, and/or altering the environmental conditions) [25]. Although no study has focused on antagonistic mechanisms of Trichoderma fungi against Termitomyces, Um et al. [26] stated that "Trichoderma will rapidly overgrow the termite fungus when termite workers are absent."

Interestingly, recent studies showed that $O$. formosanus has evolved certain strategies to suppress Trichoderma fungi. For example, the symbiotic microbes (e.g., actinobacteria and Bacillus spp.) associated with $O$. formosanus can inhibit the growth of Trichoderma fungi that is harmful to the fungus combs [24,26-28]. In an earlier study, we showed that $O$. formosanus workers made significantly shorter tunnels in the sand containing commercially formulated conidia of Trichoderma viride Pers. ex Fries than in untreated sand [29], which provided the first evidence of "spatial avoidance" performed by fungus-growing higher termites responding to an antagonistic fungus against Termitomyces. However, two questions remained: (1) Do different species in the genus Trichoderma exert general repellent effects against $O$. formosanus? (2) Do workers and adults of $O$. formosanus perform similar behaviors reacting to Trichoderma fungi?

In the present study, we conducted a series of choice tests to evaluate tunneling and aggregation behaviors of $O$. formosanus workers responding to sand/soil treated with conidia of seven Trichoderma fungi (Trichoderma longibrachiatum Rifai, Trichoderma koningii Oud., Trichoderma harzianum Rifai, Trichoderma hamatum (Bon.) Bain, Trichoderma atroviride Karsten, Trichoderma spirale Indira and Kamala, and T. viride). We also investigated the colony-initiation preference of paired adults of $O$. formosanus to soil treated with Trichoderma conidia (T. longibrachiatum and T. koningii) versus untreated soil. This study not only enhances the understanding of interactions among fungus-growing higher termites and microbes that antagonize their fungal combs, but also brings new insight into the management of O. formosanus by using Trichoderma fungi as a potential repellent agent for this termite. 


\section{Materials and Methods}

\subsection{Termites}

Eight colony groups of $O$. formosanus workers were searched and collected from different locations (>100 $\mathrm{m}$ apart from each other) in the arboretum of South China Agricultural University (SCAU). In each location, logs containing a large number of termites were collected and brought to the laboratory within $1 \mathrm{~h}$. Termites were extracted by gently knocking the logs with a hammer.

Adult $O$. formosanus were collected under road lights using insect nets during mating flights in May 2018. The species of winded adults was confirmed based on morphological characteristics described by Huang et al. [30]. Collected adults were maintained in plastic containers (diameter of upper side $=15.0 \mathrm{~cm}$, diameter of bottom side $=13.5 \mathrm{~cm}$, and height $=19.5 \mathrm{~cm}$ ) with wet filter papers, and brought to the laboratory within $1 \mathrm{~h}$. When the male and female adults began to follow or engage in tandem running one-to-one, they were paired and transferred to a new container and kept in an environmental chamber setting at $25^{\circ} \mathrm{C}$. In total, 140 pairs of $O$. formosanus adults were obtained to set the bioassays.

\subsection{Soil and Sand}

Topsoil was collected in the arboretum of SCAU $\left(23^{\circ} 9^{\prime} 28^{\prime \prime} \mathrm{N}, 113^{\circ} 21^{\prime} 16^{\prime \prime}\right.$ E) where O. formosanus was detected. A sample of soil was sent to the Laboratory of Forestry and Soil Ecology (College of Forestry and Landscape Architecture, SCAU), and identified as sandy clay loam (69.89\% sand, $9.25 \%$ silt, and $20.86 \%$ clay). Soil was sterilized at $80{ }^{\circ} \mathrm{C}$ for 3 days, and completely dried at $50{ }^{\circ} \mathrm{C}$ for $>2$ weeks. Dried soil was then ground with wooden mortars and pestles, and sifted through a 2-mm sieve to remove plant roots and other coarse particles. Fine sand, which was purchased online, was washed several times to remove impurities and sterilized and dried the same way as mentioned above. The dried sand was then sifted through a $0.85-\mathrm{mm}$ sieve to remove coarse particles.

\subsection{Trichoderma Fungi}

Seven species of Trichoderma fungi were used in the present study. T. koningii, T. viride and T. harzianum were purchased from the Guangdong Culture Collection Center (GCCC), and T. longibrachiatum, T. hamatum, T. atroviride, and T. spirale were purchased from the China General Microbiological Culture Collection Center (CGMCC) (Table 1). These fungi were cultured in the potato dextrose agar (PDA) medium in an environmental chamber set at $28 \pm 1^{\circ} \mathrm{C}$. After conidia grew on the surface, $5 \mathrm{~mL}$ sterile distilled water was added into the PDA medium to obtain the conidial suspensions, which were then transferred to a $500 \mathrm{~mL}$ Erlenmeyer flask containing rice medium $(50 \mathrm{~mL}$ distilled water and $50 \mathrm{~g}$ dried rice sterilized at $121^{\circ} \mathrm{C}$ for $20 \mathrm{~min}$ [31,32]). After 7-10 days, $200 \mathrm{~mL}$ sterile distilled water was added into the rice medium, and the flask was shaken for $5 \mathrm{~min}$ using a vortexer. The concentration of conidial suspensions was determined using a hemocytometer (Shanghai Qijing Biochemical Reagent Instrument Co., Ltd., Shanghai, China). The required amount of conidial suspensions and sterile distilled water were added into the dried sand or soil to reach a relative moisture level of $50 \%$ and final concentration of $2.5 \times 10^{7}$ conidia/g sand or soil.

Table 1. Information of seven Trichoderma fungi tested in the present study.

\begin{tabular}{|c|c|c|}
\hline Trichoderma fungi & Strain No. & Source \\
\hline Trichoderma longibrachiatum Rifai & Bio-68049 & CGMCC $^{a}$ \\
\hline Trichoderma koningii Oud. & GIM-3.518 & GCCC $^{b}$ \\
\hline Trichoderma harzianum Rifai & GIM-3.442 & GCCC \\
\hline Trichoderma hamatum (Bon.) Bain & Bio-08848 & CGMCC \\
\hline Trichoderma atroviride Karsten & Bio-08876 & CGMCC \\
\hline Trichoderma viride Pers. ex Fries & GIM-3.432 & GCCC \\
\hline Trichoderma spirale Indira and Kamala & Bio-088439 & CGMCC \\
\hline
\end{tabular}




\subsection{Tunneling-Choice Test}

This test aimed to investigate the tunneling preferences of $O$. formosanus workers on sand treated with the conidia of each Trichoderma fungus (T. longibrachiatum, T. koningii, T. harzianum, T. hamatum, T. atroviride, T. viride, or T. spirale) and untreated sand. In total, seven tunneling-choice tests were conducted, and each test was repeated 24 times (eight colony groups $\times$ three replicates for each colony group).

The method provided by Gautam and Henderson [33] was modified to conduct the bioassays. In brief, a two-dimensional tunneling arena $(150 \mathrm{~mm}(\mathrm{~L}) \times 150 \mathrm{~mm}(\mathrm{~W}) \times 1.5 \mathrm{~mm}(\mathrm{H}))$ was created by assembling two square acrylic plates $(156 \mathrm{~mm}(\mathrm{~L}) \times 156 \mathrm{~mm}(\mathrm{~W}) \times 3.0 \mathrm{~mm}(\mathrm{H}))$ and four narrow edge strips $(156 / 150 \mathrm{~mm}(\mathrm{~L}) \times 3.0 \mathrm{~mm}(\mathrm{~W}) \times 1.5 \mathrm{~mm}(\mathrm{H}))$ (Figure 1A). A 5-mm hole (entrance for termites) was drilled on the bottom center of an acrylic container (diameter $=30 \mathrm{~mm}$; height $=15 \mathrm{~mm}$ ) and the central point of the upper plate of tunneling arena. The acrylic container was then pasted on the upper plate (the holes were connected). Four small pieces of wet balsa wood slats $(10 \mathrm{~mm}(\mathrm{~L}) \times 10 \mathrm{~mm}(\mathrm{~W}) \times$ $1.0 \mathrm{~mm}(\mathrm{H})$ ) were placed on corners of the tunneling arena. The tunneling arena was divided equally into two parts: one part was filled with untreated sand, and the other was filled with sand treated with conidia of Trichoderma fungus (the entrance was right on the boundary of treated and untreated sand). The upper and bottom plates were tightly held using binding clips. Fifty $O$. formosanus workers were released into the acrylic container. The tunneling arenas were then kept in an environmental chamber ( $25 \pm 1{ }^{\circ} \mathrm{C}$ under total darkness) with randomly assigned cardinal directions.
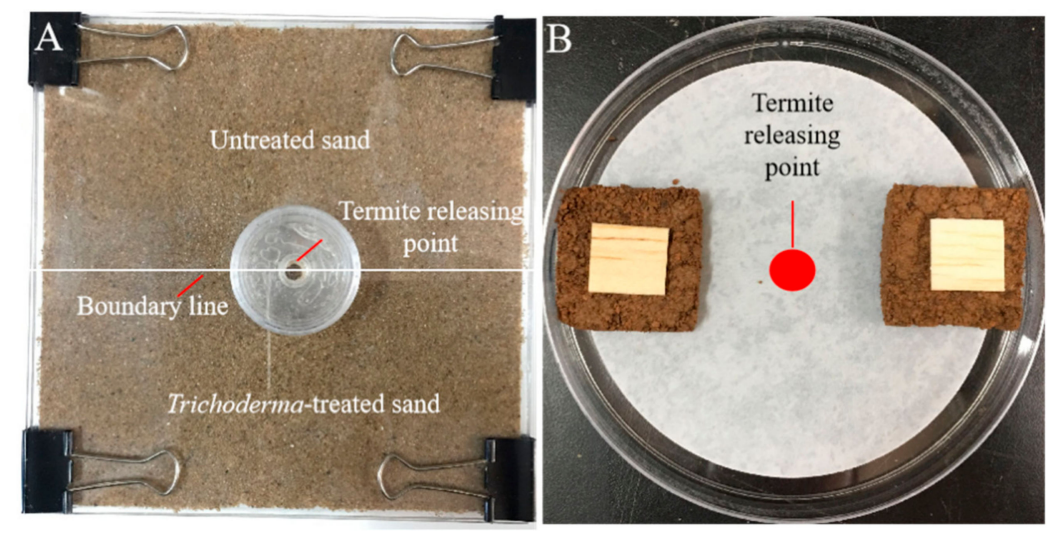

Figure 1. (A) Bioassay arenas of tunneling-choice tests, and (B) bioassay arenas of aggregation-choice tests and colony-initiation-choice tests.

After 2 days, the tunneling arenas were horizontally placed on a LED panel light (the bottom plate was placed upward). A piece of graph paper $(12 \mathrm{~mm} \times 12 \mathrm{~mm}$, each centimeter was divided by 10 lines $)$ was placed on the bottom plate as the scale, and a high-quality photograph of the tunneling arena was taken. The ImageJ software (US National Institutes of Health, Bethesda, MD, USA) was used to measure the length and area of tunnels in each part of the tunneling arena (Trichoderma-treated or untreated).

\subsection{Aggregation-Choice Test}

This test aimed to investigate the aggregation preferences of free-moving O. formosanus workers in the arenas containing soil treated with each Trichoderma fungus and untreated soil. In total, seven aggregation-choice tests were performed, and each test was repeated 24 times (eight colony groups $\times$ three replicates for each colony).

The protocols provided by Wang et al. [34] were modified to conduct the bioassays. For each test, a piece of filter paper (diameter $=12.5 \mathrm{~cm}$ ) was placed on the bottom of a Petri dish (diameter $=140 \mathrm{~mm}$; height $=13.5 \mathrm{~mm}$ ), and $2 \mathrm{~mL}$ sterile distilled water was added to moisten the filter paper (Figure 1B). The same amount $(25 \mathrm{~g})$ of Trichoderma-treated soil or untreated soil was weighed, and acrylic molds were used to prepare soil blocks $(40 \mathrm{~mm}(\mathrm{~L}) \times 40 \mathrm{~mm}(\mathrm{~W}) \times 10 \mathrm{~mm}(\mathrm{H}))$. The Trichoderma-treated soil block was placed on one side of the Petri dish, and the untreated soil block was placed on the other 
side. Balsa wood slats $(20 \mathrm{~mm}(\mathrm{~L}) \times 20 \mathrm{~mm}(\mathrm{~W}) \times 1.0 \mathrm{~mm}(\mathrm{H}))$ were immersed in the sterile distilled water for $4 \mathrm{~h}$, and one slat was randomly selected and placed on each soil block. Fifty O. formosanus workers were released into each Petri dish from the center point. Bioassay arenas were then sealed and placed in an environmental chamber set at $25 \pm 1^{\circ} \mathrm{C}$ under total darkness (the cardinal directions of Petri dishes were randomly assigned). After $24 \mathrm{~h}$, we counted the number of workers stayed on the bottom of Petri dishes. The Trichoderma-treated and untreated soil blocks were then dismantled, and the number of termites aggregated in/on soil was counted. Only live termites were recorded here.

\subsection{Colony-Initiation-Choice Test}

This test aimed to investigate the preference of paired $O$. formosanus adults to soil treated with Trichoderma fungus and untreated soil. Due to the limited number of $O$. formosanus adults collected during the mating flight season, only two Trichoderma fungi (T. longibrachiatum and T. koningii) were investigated in this study. We chose these fungi because they showed opposite effects on the aggregation behaviors of $O$. formosanus workers (see results). The choice test for T. longibrachiatum and T. koningii was repeated 68 and 69 times, respectively.

Similar procedures mentioned in the aggregation-choice tests were used to set the bioassays. One pair of adults was released into the center of each Petri dish. Bioassay arenas were sealed and maintained in an environmental chamber $\left(25 \pm 1{ }^{\circ} \mathrm{C}\right.$ under total darkness) with randomly assigned cardinal directions. The location of adults in each Petri dish was recorded each day. On day 8 , we opened the Petri dishes and dismantled the soil blocks to determine the location (in Trichoderma-treated or untreated soil blocks or on the bottom of Petri dishes) of adults as well as eggs laid by adults. Because this test focused on the colony-initiation preference by a pair of adults, we only analyzed data obtained from the assays in which (1) both male and female adults were alive, and (2) both adults stayed in the same location (i.e., assays with split adults was discarded).

\subsection{Data Analyses}

For the tunneling-choice tests, the tunnel length and area were compared using two-way analysis of variance (ANOVA, Proc Mixed, SAS 9.4, SAS Institute, Cary, NC, USA) with colony group as the random effect and sand (Trichoderma-treated or untreated sand) as the fixed effect. For the aggregation-choice tests, In-ratio transformation was conducted to transform the percentage of $O$. formosanus workers in each location to the independent data $[35,36]$. The transformed data were then compared using two-way ANOVAs with the colony group as the random effect and location as the fixed effect. Tukey's HSD tests were conducted after each ANOVA for multiple comparisons. For the colony-initiation-choice tests, chi-square tests were performed to compare the three proportions (proportions of paired adults that stayed/laid eggs in Trichoderma-treated or untreated soil blocks, or on the bottom of Petri dishes) using R 3.5.2, and the method provided by MacDonald and Gardner [37] was used for post-hoc comparisons.

\section{Results}

\subsection{Tunneling-Choice Tests}

Compared with untreated sand, O. formosanus workers produced significantly fewer tunnels (measured as both tunnel length and area) in sand containing conidia of T. longibrachiatum, T. hamatum, T. atroviride, T. viride, or T. spirale (Table 2). The tunnel area in sand treated with conidia of T. koningii was significantly lower than that in untreated sand, but the tunnel length was not significantly different (Table 2). In addition, there was no significant difference in tunnel length or area when compared sand treated with conidia of T. harzianum and untreated sand (Table 2). 
Table 2. Length and area of tunnels made by Odontotermes formosanus workers in each part of tunneling arena containing Trichoderma-treated and untreated sand. Data are presented as means \pm SEs. Different letters within the same row indicate significant differences $(p<0.05)$. N.A. indicates no significant repellent or attractive effect was detected.

\begin{tabular}{|c|c|c|c|c|c|c|c|}
\hline \multirow{2}{*}{ Test } & \multirow{2}{*}{ Measurement } & \multirow{2}{*}{ Treated Sand } & \multirow{2}{*}{ Untreated Sand } & \multicolumn{3}{|c|}{ Two-Way ANOVA } & \multirow{2}{*}{ Effect } \\
\hline & & & & $F$ & d.f. & $p$ & \\
\hline \multirow{2}{*}{$\begin{array}{c}\text { Trichoderma } \\
\text { longibrachiatum }\end{array}$} & Length (mm) & $505.0 \pm 22.1 \mathrm{~b}$ & $583.5 \pm 26.7 \mathrm{a}$ & 6.60 & 1,32 & 0.0151 & Repellent \\
\hline & Area $\left(\mathrm{mm}^{2}\right)$ & $1322.6 \pm 106.5 b$ & $1645.3 \pm 90.0 \mathrm{a}$ & 8.56 & 1,32 & 0.0063 & Repellent \\
\hline \multirow{2}{*}{$\begin{array}{l}\text { Trichoderma } \\
\text { koningii }\end{array}$} & Length (mm) & $523.2 \pm 23.7 \mathrm{a}$ & $563.8 \pm 26.9 a$ & 1.86 & 1,32 & 0.1826 & N.A. \\
\hline & Area $\left(\mathrm{mm}^{2}\right)$ & $1364.4 \pm 80.6 \mathrm{~b}$ & $1609.2 \pm 78.2 \mathrm{a}$ & 8.37 & 1,32 & 0.0068 & Repellent \\
\hline \multirow{2}{*}{$\begin{array}{l}\text { Trichoderma } \\
\text { harzianum }\end{array}$} & Length (mm) & $435.8 \pm 25.6 \mathrm{a}$ & $410.0 \pm 14.2 \mathrm{a}$ & 1.28 & 1,32 & 0.2670 & N.A \\
\hline & Area $\left(\mathrm{mm}^{2}\right)$ & $1497.0 \pm 92.3 \mathrm{a}$ & $1507.7 \pm 75.1 \mathrm{a}$ & 0.02 & 1,32 & 0.9028 & N.A \\
\hline \multirow{2}{*}{$\begin{array}{l}\text { Trichoderma } \\
\text { hamatum }\end{array}$} & Length (mm) & $388.9 \pm 17.1 b$ & $471.4 \pm 20.5 \mathrm{a}$ & 10.89 & 1,32 & 0.0024 & Repellent \\
\hline & Area $\left(\mathrm{mm}^{2}\right)$ & $1228.6 \pm 58.5 b$ & $1559.3 \pm 67.0 \mathrm{a}$ & 25.25 & 1,32 & $<0.0001$ & Repellent \\
\hline \multirow{2}{*}{$\begin{array}{l}\text { Trichoderma } \\
\text { atroviride }\end{array}$} & Length (mm) & $410.9 \pm 18.3 b$ & $506.4 \pm 23.8 \mathrm{a}$ & 19.27 & 1,32 & 0.0001 & Repellent \\
\hline & Area $\left(\mathrm{mm}^{2}\right)$ & $1281.9 \pm 51.9 b$ & $1702.6 \pm 78.4 \mathrm{a}$ & 35.51 & 1,32 & $<0.0001$ & Repellent \\
\hline \multirow{2}{*}{ Trichoderma viride } & Length (mm) & $428.9 \pm 21.3 b$ & $504.9 \pm 20.3 a$ & 9.67 & 1,32 & 0.0039 & Repellent \\
\hline & Area $\left(\mathrm{mm}^{2}\right)$ & $1466.2 \pm 77.4 \mathrm{~b}$ & $1710.9 \pm 71.2 \mathrm{a}$ & 6.12 & 1,32 & 0.0189 & Repellent \\
\hline \multirow{2}{*}{ Trichoderma spirale } & Length (mm) & $409.9 \pm 26.7 \mathrm{~b}$ & $504.8 \pm 20.9 \mathrm{a}$ & 11.86 & 1,32 & 0.0016 & Repellent \\
\hline & Area $\left(\mathrm{mm}^{2}\right)$ & $1366.8 \pm 103.0 \mathrm{~b}$ & $1739.0 \pm 102.2 \mathrm{a}$ & 17.11 & 1,32 & 0.0002 & Repellent \\
\hline
\end{tabular}




\subsection{Aggregation-Choice Test}

The mean survivorship of $O$. formosanus workers was $>98.5 \%$ in each aggregation-choice test. The percentages of termites in soil blocks containing conidia of T. koningii, T. atroviride, and T. spirale were significantly lower compared with untreated ones (Table 3 ). However, significantly more termites were found in soil blocks containing conidia of T. longibrachiatum or T. hamatum compared with untreated ones (Table 3). These were similar percentages of termites in soil blocks containing the conidia of T. harzianum or T. viride and untreated ones (Table 3).

Table 3. Percentages of Odontotermes formosanus workers that aggregated in the Trichoderma-treated or untreated soil blocks, or stayed on the Petri dishes. Data are presented as means \pm SEs. Different letters within the same row indicate significant differences $(p<0.05)$. N.A. indicates no significant repellent or attractive effect was detected.

\begin{tabular}{|c|c|c|c|c|c|c|c|}
\hline \multirow{2}{*}{ Test } & \multirow{2}{*}{$\begin{array}{c}\text { Treated } \\
\text { Block }\end{array}$} & \multirow{2}{*}{ Petri Dish } & \multirow{2}{*}{$\begin{array}{l}\text { Untreated } \\
\text { Block }\end{array}$} & \multicolumn{3}{|c|}{ Statistical Result } & \multirow{2}{*}{ Effect } \\
\hline & & & & $F$ & d.f. & $p$ & \\
\hline Trichoderma longibrachiatum & $66.9 \pm 4.1 \mathrm{a}$ & $18.0 \pm 3.0 \mathrm{~b}$ & $15.2 \pm 3.0 \mathrm{~b}$ & 97.87 & 2,48 & $<0.0001$ & Attractive \\
\hline Trichoderma koningii & $24.0 \pm 3.5 b$ & $17.9 \pm 3.4 \mathrm{~b}$ & $58.1 \pm 4.6 \mathrm{a}$ & 36.40 & 2,48 & $<0.0001$ & Repellent \\
\hline Trichoderma harzianum & $53.2 \pm 5.9 \mathrm{a}$ & $12.1 \pm 2.7 \mathrm{~b}$ & $34.7 \pm 5.4 \mathrm{a}$ & 23.15 & 2,48 & $<0.0001$ & N.A \\
\hline Trichoderma hamatum & $71.6 \pm 5.2 \mathrm{a}$ & $3.5 \pm 1.3 c$ & $24.9 \pm 5.1 b$ & 90.17 & 2,48 & $<0.0001$ & Attractive \\
\hline Trichoderma atroviride & $37.1 \pm 6.5 b$ & $5.8 \pm 0.8 \mathrm{c}$ & $57.1 \pm 6.5 \mathrm{a}$ & 32.28 & 2,48 & $<0.0001$ & Repellent \\
\hline Trichoderma viride & $55.7 \pm 6.5 \mathrm{a}$ & $4.8 \pm 0.9 \mathrm{~b}$ & $39.5 \pm 6.4 \mathrm{a}$ & 37.59 & 2,48 & $<0.0001$ & N.A \\
\hline Trichoderma spirale & $34.2 \pm 5.0 \mathrm{~b}$ & $10.0 \pm 2.0 \mathrm{c}$ & $55.8 \pm 4.2 \mathrm{a}$ & 68.49 & 2,48 & $<0.0001$ & Repellent \\
\hline
\end{tabular}

\subsection{Colony-Initiation-Choice Test}

Similar proportions of paired adults stayed in soil blocks containing Trichoderma conidia (T. longibrachiatum or T. koningii) and untreated ones throughout the experiments (Figure 2, statistical results are shown in Table 4). For the choice test of T. longibrachiatum, a significantly higher proportion of paired adults stayed on the bottom of Petri dishes than that in untreated soil blocks on day 2 (Figure 2A). In addition, there was no significant difference in the proportion of paired adults that laid eggs in Trichoderma-treated and untreated soil blocks (Table 5).
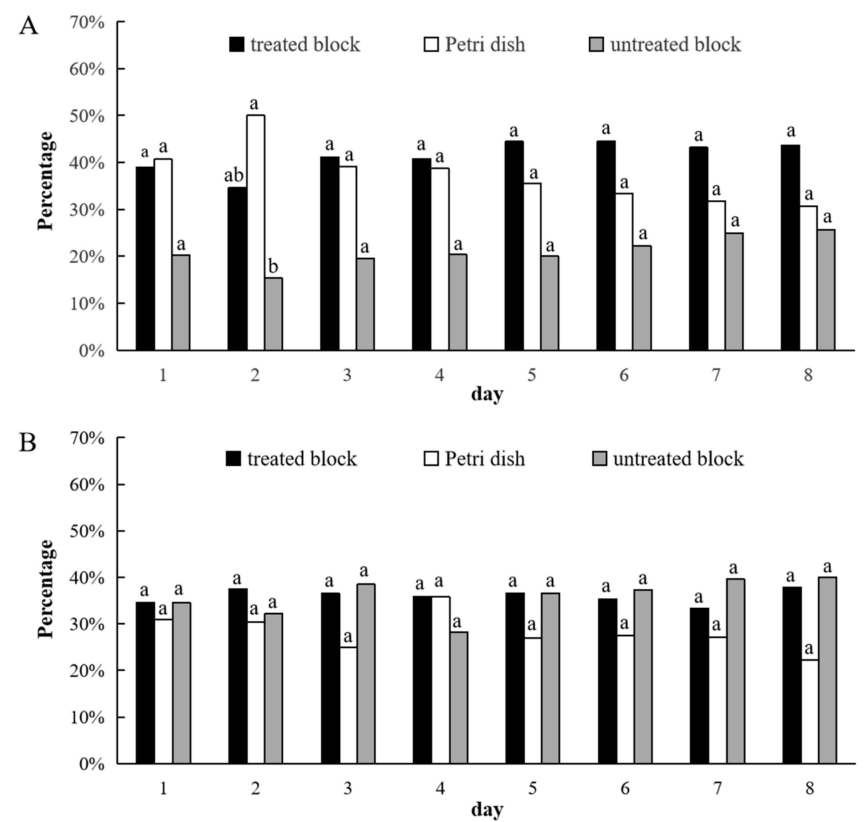

Figure 2. Percentages of paired adults of Odontotermes formosanus that stayed in soil blocks treated with conidia of (A) Trichoderma longibrachiatum or (B) Trichoderma koningii, or untreated soil blocks, or on the bottom of Petri dishes. Different letters within each day indicate significant differences $\left(p<\frac{0.05}{3}\right.$ with Bonferroni correction [34]). 
Table 4. Statistical results of chi-square tests to compare the proportions of paired Odontotermes formosanus adults that stayed in Trichoderma-treated or untreated soil blocks, or on the bottom of Petri dishes.

\begin{tabular}{ccccc}
\hline Test & Day & $\boldsymbol{\chi}^{\mathbf{2}}$ & $\mathbf{d f}$ & $\boldsymbol{p}$ \\
\hline Trichodermalongibrachiatum & 1 & 5.1475 & 2 & 0.0762 \\
& 2 & 6.1455 & 2 & 0.0463 \\
& 3 & 4.3529 & 2 & 0.1134 \\
& 4 & 3.7143 & 2 & 0.1561 \\
Trichodermakoningii & 5 & 4.1333 & 2 & 0.1266 \\
& 6 & 3.3333 & 2 & 0.1889 \\
& 7 & 2.2273 & 2 & 0.3284 \\
& 8 & 2.0000 & 2 & 0.3679 \\
& 1 & 0.1455 & 2 & 0.9299 \\
& 2 & 0.4643 & 2 & 0.7928 \\
& 3 & 1.6538 & 2 & 0.4374 \\
& 4 & 0.6038 & 2 & 0.7394 \\
& 5 & 0.9615 & 2 & 0.6183 \\
& 6 & 0.8235 & 2 & 0.6625 \\
& 7 & 1.1250 & 2 & 0.5698 \\
& 8 & 2.5333 & 2 & 0.2818 \\
\hline
\end{tabular}

Table 5. Percentage of paired Odontotermes formosanus adults laid eggs in Trichoderma-treated or untreated soil blocks, or on the bottom of Petri dishes. No significant difference was detected among the three proportions for each test $(p>0.05)$.

\begin{tabular}{ccccc}
\hline Test & Treated Block & Petri Dish & Untreated Block & Statistical Results \\
\hline Trichodermalongibrachiatum & 40.0 & 36.7 & 23.3 & $\chi^{2}=1.4000 ; \mathrm{df}=2 ; p=0.4966$ \\
Trichoderma koningii & 37.8 & 22.2 & 40.0 & $\chi^{2}=2.5333 ; \mathrm{df}=2 ; p=0.2817$ \\
\hline
\end{tabular}

\section{Discussion}

Earlier studies showed that the conidia of entomopathogenic fungi were repellent to both fungus-growing higher termites, such as Macrotermes michaelseni (Sjöstedt) [14,15], and wood-feeding lower termites, such as C. formosanus [16,17]. However, not all strains of entomopathogenic fungi have been shown to repel termites. For example, Wright et al. [38] reported that neither Isaria fumosorosea Wize strain ARSEF 3581 nor Metarhizium anisopliae (Metschn.) Sorokin strain NRRL 30905 was repellent against $C$. formosanus in different substrates (sand, soil, and sawdust). Bodawatta et al. [39] reported that the fungus-growing termite Macrotermes natalensis (Haviland) did not avoid substrate containing the entomopathogenic fungus Beauveria bassiana (Balsamo) Vuillemin isolate \#122. Mburu et al. [14,15] reported that the repellency of entomopathogenic fungi was determined by their virulence, volatiles, and genotypes. In general, entomopathogenic fungi with higher virulence have stronger repellency against termites [14].

Although Trichoderma fungi are not pathogenic to termites, they antagonize Termitomyces cultured by the fungus-growing higher termites. Our previous work showed that commercially formulated conidia of T. viride repelled tunneling behavior of $O$. formosanus [29]. In the present study, we found that unformulated conidia of six Trichoderma fungi significantly decreased the tunneling behaviors of O. formosanus (Table 2), indicating that O. formosanus showed general avoidance behaviors in response to different fungal species in the genus Trichoderma. This avoidance may be triggered by chemical cues in the substrate associated with Trichoderma fungi. As a subterranean species, O. formosanus workers spend the majority of their time in underground nests and tunnels. The avoidance behavior may effectively decrease the chance of direct contact between termites and Trichoderma conidia; therefore, reducing the risk of introducing antagonistic fungi into the fungal combs.

It is important to note that the Trichoderma fungi can establish long-lasting colonization with plant root systems and inhibit various phytopathogens due to their strong antagonistic and mycoparasitic 
activities [25,40-42]. Therefore, many Trichoderma fungi and strains have been used as biocontrol agents to treat the agricultural and forest soil [43]. Our results indicated that introducing the Trichoderma fungi into soil may also reduce the infestation of $O$. formosanus. In addition, compared with large adult trees, seedlings are more likely to be killed or seriously damaged by O. formosanus. Treating the roots of seedlings with Trichoderma fungi before planting may help to repel $O$. formosanus. Performing field studies to verify those potential applications would be valuable.

The spatial avoidance of harmful microbes has also been commonly described in other social insects such as ants [44-47]. However, Pontieri et al. [48] found that colonies of the pharaoh ant, Monomorium pharaonis (L.), preferred to move into nests infected with Metarhizium brunneum Petch compared with the uninfected ones. Likewise, the founding queens of Formica selysi Bondroit showed an initial preference to the nests contaminated by M. brunneum and B. bassiana compared with the nest sites without entomopathogenic fungi, whereas no colony-initiation preference was observed in response to a non-entomopathogenic fungus Petromyces alliaceus Malloch and Cain or heat-killed B. bassiana [49]. The mechanisms for these "surprising" results are still unclear, but Pontieri et al. [48] provided some possible explanations: (1) the conidia of entomopathogenic fungi used in these studies did not represent a strong lethal effect on ants; (2) the social contact between ants and entomopathogenic fungi in new nest sites can "reduce the susceptibility of nestmates to later exposure to the same pathogen." In the present study, though conidia of T. longibrachiatum and T. hamatum reduced the tunneling activities of O. formosanus workers (Table 2), they attracted termites in the aggregation-choice tests (Table 3). Additionally, more paired adults of $O$. formosanus stayed and laid eggs in the soil blocks treated with T. longibrachiatum than that of the untreated ones (Figure 2), though the difference was not significant. It appears that some Trichoderma fungi triggered different decision-making processes when workers and adults of $O$. formosanus selected tunneling sites and aggregation/nesting locations.

Interestingly, Trichoderma fungi may affect wood-feeding lower termites and fungus-growing higher termites differently (Figure 3). Previous studies showed that many Trichoderma fungi can be isolated from bodies of C. formosanus [50,51] and Reticulitermes flavipes (Kollar) [52]. Our previous studies showed that $C$. formosanus built more tunnels in sand treated with conidia of T. viride or T. harzianum compared with untreated sand [29]. The positive associations and tunneling preferences may be due to the beneficial effects of Trichoderma fungi on the lower termites. Mankowski et al. [53] showed that wood exposed to T. viride positively affected symbiotic protozoa in the gut of Pacific dampwood termite Zootermopsis angusticollis Hagen. Jayasimha and Henderson [50,51] reported that Trichoderma fungi isolated from the cuticle and guts of $C$. formosanus can inhibit the growth of a rotting fungus Gloeophyllum trabeum (Pers.) Murrill which compete for the cellulose with termites. Additionally, our preliminary studies showed that the half lethal time $\left(\mathrm{LT}_{50}\right)$ of $C$. formosanus workers exposed to Trichoderma fungi and M. anisopliae simultaneously was significantly longer than that of the termite workers exposed to $M$. anisopliae alone. This indicates that Trichoderma fungi may protect C. formosanus from infection (Wen and Wang, unpublished data). These results showed that the higher fungus-growing termites and lower wood-feeding termites have evolved different associations with Trichoderma fungi. We are currently comparing the behavioral and electroantennogram responses between $O$. formosanus and $C$. formosanus in response to volatiles of Trichoderma fungi to investigate the mechanisms accounting for such differences. 


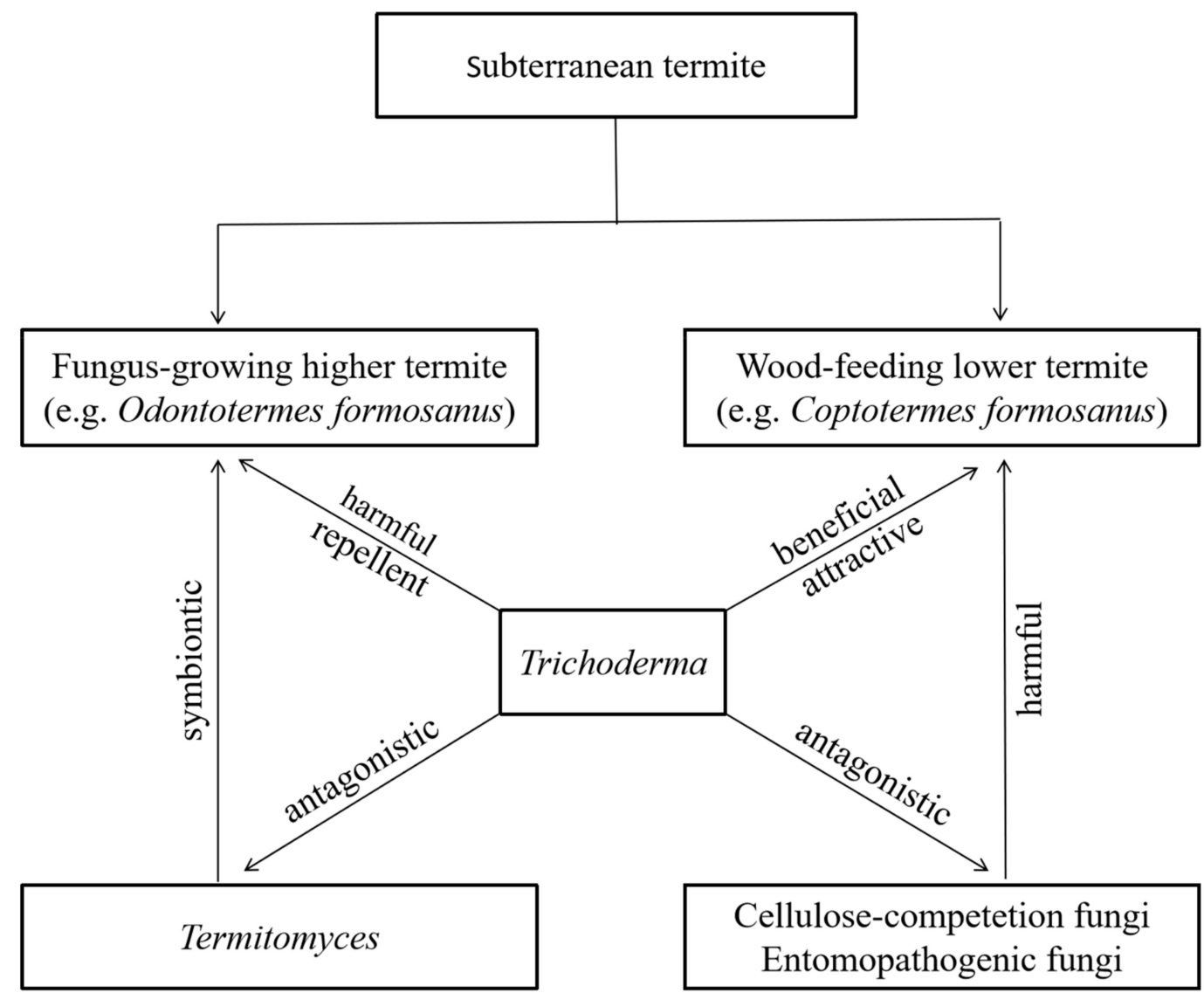

Figure 3. An overview of interactions between Trichoderma fungi and fungus-growing higher termites or wood-feeding lower termites. In general, Trichoderma fungi inhibited the tunneling activities of the fungus-growing higher termite, Odontotermes formosanus (as shown in the present study), and they are antagonistic to the Termitomyces cultured by fungus-growing termites [24]. On the contrary, Trichoderma fungi attract the wood-feeding lower termite, Coptotermes formosanus [29], and benefit this termite by antagonizing the entomopathogenic fungi and cellulose-competition fungi [50,51].

\section{Conclusions}

In the present study, we found that $O$. formosanus workers made significantly fewer tunnels in sand containing conidia of six Trichoderma fungi (T. longibrachiatum, T. koningii, T. hamatum, T. atroviride, T. viride, and T. spirale) compared with untreated soil. Results indicated that $O$. formosanus workers may have evolved behavioral strategies to reduce contact with Trichoderma fungi in the substrate that antagonize symbiotic Termitomyces fungi cultured by the termites. Based on these results, we suggest introducing Trichoderma fungi into soil or treating the roots of seedlings with Trichoderma conidia to protect plants from $O$. formosanus infestation. Field studies are needed to evaluate these potential applications. In addition, the aggregation-choice test showed that T. koningii, T. atroviride, and T. spirale repelled $O$. formosanus workers, whereas T. longibrachiatum and T. hamatum attracted termites, indicating that Trichoderma fungi may exert varied effects on the aggregation preference by $O$. formosanus workers. Future studies will address differential responses on termite tunneling and aggregation triggered by Trichoderma fungi.

Author Contributions: Methodology, C.W.; formal analysis, H.X., J.C., and X.C.; investigation, H.X., S.L., and C.W.; resources, H.X., X.W., and C.W.; writing-original draft preparation, H.X. and C.W.; writing-review and editing, H.X., J.C., X.C., S.L., X.W., and C.W.; visualization, H.X., J.C., and C.W.; supervision, X.W. and C.W.; project administration, C.W.; funding acquisition, C.W.

Funding: This research was funded by the National Natural Science Foundation of China (31500530). 
Acknowledgments: We thank Zhengya Jin, Wenquan Qin, and Qinxi Xie (College of Forestry and Landscape Architecture, South China Agricultural University) for valuable help with collecting O. formosanus workers and adults.

Conflicts of Interest: The authors declare no conflict of interest.

\section{References}

1. Rust, M.K.; Su, N.Y. Managing social insects of urban importance. Annu. Rev. Entomol. 2012, 57, 355-375. [CrossRef] [PubMed]

2. Denier, D.; Bulmer, M.S. Variation in subterranean termite susceptibility to fatal infections by local Metarhizium soil isolates. Insects Soc. 2015, 62, 219-226. [CrossRef]

3. Hussain, A.; Li, Y.F.; Cheng, Y.; Liu, Y.; Chen, C.C.; Wen, S.Y. Immune-related transcriptome of Coptotermes formosanus Shiraki workers: The defense mechanism. PLoS ONE 2013, 8, e69543. [CrossRef] [PubMed]

4. Hamilton, C.; Lay, F.; Bulmer, M.S. Subterranean termite prophylactic secretions and external antifungal defenses. J. Insect Physiol. 2011, 57, 1259-1266. [CrossRef] [PubMed]

5. Peterson, B.F.; Scharf, M.E. Lower termite associations with microbes: Synergy, protection, and interplay. Front. Microbiol. 2016, 7, 422. [CrossRef]

6. Chouvenc, T.; Elliott, M.L.; Šobotník, J.; Efstathion, C.A.; Su, N.Y. The termite fecal nest: A framework for the opportunistic acquisition of beneficial soil Streptomyces (Actinomycetales: Streptomycetaceae). Environ. Entomol. 2018, 47, 1431-1439. [CrossRef]

7. Myles, T.G. Alarm, aggregation, and defense by Reticulitermes flavipes in response to a naturally occurring isolate of Metarhizium anisopliae. Sociobiology 2002, 40, 243-256.

8. Bulmer, M.S.; Franco, B.A.; Fields, E.G. Subterranean termite social alarm and hygienic responses to fungal pathogens. Insects 2019, 10, 240. [CrossRef]

9. Mankowski, M.E.; Kaya, H.K.; Grace, K.J.; Sipes, B. Differential susceptibility of subterranean termite castes to entomopathogenic nematodes. Biocontrol Sci. Technol. 2005, 15, 367-377. [CrossRef]

10. Yanagawa, A.; Yokohari, F.; Shimizu, S. Influence of fungal odor on grooming behavior of the termite, Coptotermes formosanus. J. Insect Sci. 2010, 10, 141. [CrossRef]

11. Yanagawa, A.; Fujiwara-Tsujii, N.; Akino, T.; Yoshimura, T.; Yanagawa, T.; Shimizu, S. Odor aversion and pathogen-removal efficiency in grooming behavior of the termite Coptotermes formosanus. PLoS ONE 2012, 7, e47412. [CrossRef] [PubMed]

12. Davis, H.E.; Meconcelli, S.; Radek, R.; McMahon, D.P. Termites shape their collective behavioural response based on stage of infection. Sci. Rep. 2018, 8, 14433. [CrossRef] [PubMed]

13. Chouvenc, T.; Su, N.Y. When subterranean termites challenge the rules of fungal epizootics. PLoS ONE 2012, 7, e34484. [CrossRef] [PubMed]

14. Mburu, D.M.; Ochola, L.; Maniania, N.K.; Njagi, P.G.N.; Gitonga, L.M.; Ndung'u, M.W.; Hassanali, A. Relationship between virulence and repellency of entomopathogenic isolates of Metarhizium anisopliae and Beauveria bassiana to the termite Macrotermes michaelseni. J. Insect Physiol. 2009, 55, 774-780. [CrossRef] [PubMed]

15. Mburu, D.M.; Ndung'u, M.W.; Maniania, N.K.; Hassanali, A. Comparison of volatile blends and gene sequences of two isolates of Metarhizium anisopliae of different virulence and repellency toward the termite Macrotermes michaelseni. J. Exp. Biol. 2011, 214, 956-962. [CrossRef] [PubMed]

16. Sun, J.Z.; Fuxa, J.R.; Richter, A.; Ring, D. Interactions of Metarhizium anisoplae and tree-based mulches in repellence and mycoses against Coptotermes formosanus (Isoptera: Rhinotermitidae). Environ. Entomol. 2014, 37, 755-763. [CrossRef]

17. Yanagawa, A.; Imai, T.; Akino, T.; Toh, Y.; Yoshimura, T. Olfactory cues from pathogenic fungus affect the direction of motion of termites, Coptotermes formosanus. J. Chem. Ecol. 2015, 41, 1118-1126. [CrossRef]

18. De Roode, J.C.; Lefèvre, T. Behavioral immunity in insects. Insects 2012, 3, 789-820. [CrossRef]

19. Shang, Y.; Feng, P.; Wang, C. Fungi that infect insects: Altering host behavior and beyond. PLoS Pathog. 2015, 11, e1005037. [CrossRef]

20. Cremer, S.; Pull, C.D.; Fuerst, M.A. Social immunity: Emergence and evolution of colony-level disease protection. Annu. Rev. Entomol. 2018, 63, 105-123. [CrossRef] 
21. Meyel, S.V.; Koerner, M.; Meunier, J. Social immunity: Why we should study its nature, evolution and functions across all social systems. Curr. Opin. Insect Sci. 2018, 28, 1-7. [CrossRef] [PubMed]

22. Xu, X.; Zeng, Q.; Li, D.; Wu, J.; Wu, X.; Shen, J. GPR detection of several common subsurface voids inside dikes and dams. Eng. Geol. 2010, 111, 31-42. [CrossRef]

23. Kasseney, B.D.; Deng, T.; Mo, J. Effect of wood hardness and secondary compounds on feeding preference of Odontotermes formosanus (Isoptera: Termitidae). J. Econ. Entomol. 2011, 104, 862-867. [CrossRef] [PubMed]

24. Mathew, G.M.; Ju, Y.M.; Lai, C.Y.; Mathew, D.C.; Huang, C.C. Microbial community analysis in the termite gut and fungus comb of Odontotermes formosanus: The implication of Bacillus as mutualists. FEMS. Microbiol. Ecol. 2012, 79, 504-517. [CrossRef]

25. Benítez, T.; Rincón, A.M.; Limón, M.C.; Codon, A.C. Biocontrol mechanisms of Trichoderma strains. Intern. Microbiol. 2004, 7, 249-260.

26. Um, S.; Fraimout, A.; Sapountzis, P.; Sapountzis, Oh.; Sapountzis, D.C.; Poulsen, M. The fungus-growing termite Macrotermes natalensis harbors bacillaene-producing Bacillus sp. that inhibit potentially antagonistic fungi. Sci. Rep. 2013, 3, 3250. [CrossRef]

27. Mevers, E.J.; Saurí, A.; Moser, M.; Varlan, G.E.; Martin, J.; Clardy, C. Chemical warfare: The battle between termite-associated actinobacteria and Trichoderma harzianum, a fungal pathogen. Planta. Med. 2018, 82, S1-S381.

28. Otani, S.; Challinor, V.L.; Kreuzenbeck, N.B.; Kildgaard, S.; Christensen, S.K.; Larsen, L.L.M.; Poulsen, M. Disease-free monoculture farming by fungus-growing termites. Sci. Rep. 2019, 9, 8819. [CrossRef]

29. Xiong, H.; Xue, K.; Qin, W.; Chen, X.; Wang, H.; Shi, X.; Lin, W. Does soil treated with conidial formulations of Trichoderma spp. attract or repel subterranean termites? J. Econ. Entomol. 2018, 111, 808-816. [CrossRef]

30. Huang, F.S.; Zhu, S.M.; Ping, Z.M.; He, X.S.; Li, G.X.; Gao, D.R. Isoptera; Science Press: Beijing, China, 2000; pp. 566-568.

31. Ye, S.D.; Ying, S.H.; Chen, C.; Feng, M.G. New solid-state fermentation chamber for bulk production of aerial conidia of fungal biocontrol agents on rice. Biotechnol. Lett. 2006, 28, 799-804. [CrossRef]

32. Locatelli, G.O.; dos Santos, G.F.; Botelho, P.S.; Finkler, C.L.L.; Buenod, L.A. Development of Trichoderma sp. Formulations in encapsulated granules (CG) and evaluation of conidia shelf-life. Biol. Control. 2018, 117, 21-29. [CrossRef]

33. Gautam, B.K.; Henderson, G. Laboratory study of the influence of substrate type and temperature on the exploratory tunneling by Formosan subterranean termite. Insects 2012, 3, 629-639. [CrossRef] [PubMed]

34. Wang, C.; Henderson, G.; Gautam, B.K. Behavioral response of Formosan subterranean termites (Isoptera: Rhinotermitidae) to soil with high clay content. J. Insect Behav. 2015, 28, 303-311. [CrossRef]

35. Aitchison, J. The Statistical Analysis of Compositional Data; Chapman \& Hall: London, UK; New York, NY, USA, 1986.

36. Kucera, M.; Malmgren, B.A. Logratio transformation of compositional data: A resolution of the constant sum constraint. Mar. Micropaleontol. 1998, 34, 117-120. [CrossRef]

37. MacDonald, P.L.; Gardner, R.C. Type I error rate comparisons of post hoc procedures for I $\times \mathrm{J}$ chi-square tables. Educ. Psychol. Meas. 2000, 60, 735-754. [CrossRef]

38. Wright, M.S.; Cornelius, M.L. Mortality and repellent effects of microbial pathogens on Coptotermes formosanus (Isoptera: Rhinotermitidae). BMC. Microbiol. 2012, 12, 291. [CrossRef]

39. Bodawatta, K.H.; Poulsen, M.; Bos, N. Foraging Macrotermes natalensis fungus-growing termites avoid a mycopathogen but not an entomopathogen. Insects 2019, 10, 185. [CrossRef]

40. Harman, G.E.; Howell, C.R.; Viterbo, A.; Chet, I.; Lorito, M. Trichoderma species-opportunistic, avirulent plant symbionts. Nat. Rev. Microbiol. 2004, 2, 43. [CrossRef]

41. Vinale, F.; Sivasithamparam, K.; Ghisalberti, E.L.; Marra, R.; Woo, S.L.; Lorito, M. Trichoderma-plant-pathogen interactions. Soil. Biol. Biochem. 2008, 40,1-10. [CrossRef]

42. Hermosa, R.; Viterbo, A.; Chet, I.; Monte, E. Plant-beneficial effects of Trichoderma and of its genes. Microbiology 2012, 158, 17-25. [CrossRef]

43. Verma, M.; Brar, S.K.; Tyagi, R.D.; Surampalli, R.Y.; Valéro, J.R. Antagonistic fungi, Trichoderma spp.: Panoply of biological control. Biochem. Eng. J. 2007, 37, 1-20. [CrossRef]

44. Pull, C.D.; Metzler, S.; Naderlinger, E.; Cremer, S. Protection against the lethal side effects of social immunity in ants. Curr. Biol. 2018, 28, R1139-R1140. [CrossRef] [PubMed] 
45. Lucas, J.M.; Madden, A.A.; Penick, C.A.; Epps, M.J.; Marting, P.R.; Stevens, J.L.; Fergus, D.J.; Dunn, R.R.; Meineke, E.K. Azteca ants maintain unique microbiomes across functionally distinct nest chambers. Proc. R. Soc. B 2019, 286, 20191026. [CrossRef] [PubMed]

46. Bos, N.; Sundström, L.; Fuchs, S.; Freitak, D. Ants medicate to fight disease. Evolution 2015, 69, $2979-2984$. [CrossRef]

47. Rocha, S.L.; Evans, H.C.; Jorge, V.L.; Cardoso, L.A.; Pereira, F.S.; Rocha, F.B.; Barreto, R.W.; Hart, A.G.; Elliot, S.L. Recognition of endophytic Trichoderma species by leaf-cutting ants and their potential in a Trojan-horse management strategy. R. Soc. Open Sci. 2017, 4, 160628. [CrossRef]

48. Pontieri, L.; Vojvodic, S.; Graham, R.; Pedersen, J.S.; Linksvayer, T.A. Ant colonies prefer infected over uninfected nest sites. PLoS ONE 2014, 9, e111961. [CrossRef]

49. Bruetsch, T.; Felden, A.; Reber, A.; Chapuisat, M. Ant queens (Hymenoptera: Formicidae) are attracted to fungal pathogens during the initial stage of colony founding. Myrmecol. News 2014, 20, 71-76.

50. Jayasimha, P.; Henderson, G. Fungi isolated from integument and guts of Coptotermes formosanus and their antagonistic effect on Gleophyllum trabeum. Ann. Entomol. Soc. Am. 2007, 100, 703-710. [CrossRef]

51. Jayasimha, P.; Henderson, G. Suppression of growth of a brown rot fungus, Gloeophyllum trabeum, by Formosan subterranean termites (Isoptera: Rhinotermitidae). Ann. Entomol. Soc. Am. 2007, 100, 506-511. [CrossRef]

52. Zoberi, M.H.; Grace, J.K. Fungi associated with the subterranean termite Reticulitermes flavipes in Ontario. Mycologia 1990, 82, 289-294. [CrossRef]

53. Mankowski, M.E.; Schowalter, T.D.; Morrell, J.J.; Lyons, B. Feeding habits and gut fauna of Zootermopsis angusticollis (Isoptera: Termopsidae) in response to wood species and fungal associates. Environ. Entomol. 1998, 27, 1315-1322. [CrossRef]

(C) 2019 by the authors. Licensee MDPI, Basel, Switzerland. This article is an open access article distributed under the terms and conditions of the Creative Commons Attribution (CC BY) license (http://creativecommons.org/licenses/by/4.0/). 